\title{
EFFICIENCY OF CHITOSANS FOR THE TREATMENT OF PAPERMAKING PROCESS WATER BY DISSOLVED AIR FLOTATION
}

\author{
Ruben Miranda ${ }^{a}$, Raluca Nicu ${ }^{b}$, Isabel Latour ${ }^{a}$, Mihail Lupei $^{b}$, \\ Elena Bobu', Angeles Blanco ${ }^{\mathrm{a}, *}$ \\ ${ }^{a}$ Department of Chemical Engineering, Faculty of Chemistry, Complutense University of \\ Madrid, Av. Complutense s/n, 28040 Madrid, Spain. \\ ${ }^{\mathrm{b}}$ Department of Natural and Synthetic Polymers, Faculty of Chemical Engineering and \\ Environmental Protection, "Gheorghe Asachi" Technical University of Iasi, Prof. Dr. \\ Doc. Dimitrie Mangeron 73, Iasi, 700050, Romania. \\ *Corresp. author: ablanco@quim.ucm.es. Phone: +34913944247; Fax: +34913944243.
}

\begin{abstract}
Interest has grown in bio-polymers as being environmental friendly alternatives to synthetic additives. In this work, two native chitosans with different molecular weights have been evaluated on a laboratory scale for their effectiveness for the removal of contaminants from papermaking process waters by dissolved air flotation (DAF). The use of chitosan quaternary derivatives and the use of the native chitosans in combination with anionic bentonite microparticles have also been tested. Results demonstrate a high efficiency of the native chitosan products at intermediate dosages and furthermore, their efficiency is enhanced by the combined addition of bentonite. For an equivalent removal of contaminants, the required dosage of chitosan is about half that the dosage required in absence of bentonite. Quaternary derivatives have not improved the efficiency of the native chitosan in this case. The optimum treatment would be $50 \mathrm{mg} / \mathrm{L}$ of native chitosan and $100 \mathrm{mg} / \mathrm{L}$ of bentonite where this treatment is capable of the removal of $83-89 \%$ turbidity (residual turbidity 210-320 NTU), 68-71\% dissolved turbidity (residual dissolved turbidity of $22-24$ NTU), $18-22 \%$ total solids (residual total solids of 2750 $2900 \mathrm{mg} / \mathrm{L})$ and $19-23 \%$ COD (1440-1525 mg/L). The low molecular weight native chitosan is more efficient than the medium molecular weight chitosan in all cases. The Focused Beam Reflectance Measurement (FBRM) is used to assess the aggregation process and to predict the separation efficiency of DAF units either with single or dual systems. The efficiency predicted through the FBRM technique is very similar to that obtained later in the DAF tests.
\end{abstract}

Keywords: chitosan; flocculation; bentonite; dissolved air flotation; papermaking process water.

\section{INTRODUCTION}

The pulp and paper industry is a large water consumer, the reduction of fresh water consumption being one of the most important issues in papermaking operations. One of the most frequently used strategy for reducing the fresh water consumption is the closure 
of the water circuits by reusing the process waters. However, as the mill closes the water circuits, there is a continuous accumulation of suspended and dissolved and colloidal material (DCM) in process waters, which increases nearly exponential with the reduction of fresh water consumption. While suspended solids are removed easily in the existing clarification systems, DCM is almost completely recycled into the process thus, limiting the closure of the circuits [1]. DCM negatively affects the production process causing blockings, scaling, slime formation, breaks and stickies deposits and also affects the quality of the final product by impairing its physical properties or by the presence of dirt and holes [2-4].

One of the most common processes used for the treatment of papermaking process waters is the dissolved air flotation (DAF), also called micro flotation. Water clarification by DAF is achieved in a rather quiescent environment by capture of both hydrophobic and hydrophilic solids on very fine bubbles generated by the release of air previously dissolved in pressurized water. DAF units efficiently remove $80-99 \%$ of suspended solids including fines, fillers, and a variety of contaminants such as ink particles and lipophilic extractives [5-6]. Moreover, with suitable chemicals, finely dispersed and colloidal organic particles $(>0.2 \mu \mathrm{m})$ can also be agglomerated and removed. However, the best reductions of organic DCM obtained by micro flotation, measured as COD, are not higher than $10-30 \%$ and these removal efficiencies are really a great achievement as most COD is soluble [6-10]. On the contrary, inorganic and biological DCM are almost not affected by DAF.

A variety of chemicals are used in DAF systems where common chemicals including: aluminum based products such as alum, polyaluminum chloride, aluminum chlorhidrate, polyaluminum sulfate, etc.; ferric chloride; minerals such as bentonite or talc, and organic polymers such as polyacrylamides, poly(diallyl-dimethyl-ammonium-chloride), polyamines, polyvinylamides, etc. [9]. Inorganic coagulants have been used for decades as they are cost effective and easy to handle, but these processes have a number of disadvantages: they are strongly $\mathrm{pH}$-dependant, they consume alkalinity of the waters, high dosages of coagulants are necessary, high amounts of metal hydroxide sludge are produced, and in the case, of alum and aluminum salts, its use is now very controversial due to the possible impact of residual aluminum on Alzheimer's disease [11]. On the other hand, synthetic flocculants, mainly polyacrylamide-based cationic flocculants have been greatly used in the industry due to their economic advantages and easy tailorability by controlling the molecular weight, molecular weight distribution, chemical structure of polymers, nature and ratio of functional groups on polymeric backbone. The synthetic polymers are not biodegradable and their degraded products are considered hazardous because of the release of monomers that could enter in the food chain and cause carcinogenic effects [11].

For these reasons, the search for better alternatives to the conventional coagulants has become an important challenge $[11,12]$. Increasing demand for environmentally friendly technologies promotes the interest to natural polyelectrolytes where chitosan being the most promising cationic biopolymer for extensive application [13-15]. Chitosan is a polycationic biodegradable non-toxic high molecular weight linear copolymer of 
glucosamine and $\mathrm{N}$-acetyl glucosamine, with a high charge density in the acidic to neutral solutions and it can be used as an eco-friendly coagulant/flocculant hybrid. The reactivity of chitosan for the coagulation and flocculation of suspended particles and colloids results from several mechanisms including: i) electrostatic attraction, ii) sorption, related to protonation of the amine groups of chitosan and chelating capacity due to the high content of hydroxyl groups, and iii) bridging, related to the relative high molecular weight of chitosan [12].

In acidic to neutral solutions, the amino group in chitosan is protonated resulting in a high charge density and good solubility. However, this charge density is $\mathrm{pH}$ dependent where at neutral to basic conditions, chitosan loses its charge and precipitates from solution making it unusable. For these applications, quaternization is an alternative path to produce water-soluble chitosan derivatives with a wide operational $\mathrm{pH}$ range including neutral and slight basic conditions which are common in papermaking operations due to a permanent positive charge on the polymer backbone [16-19]. In addition, this would avoid the use of carboxylic acid solutions (such as acetic acid), which could increase organics content of treated waters, or inorganic acid solutions (such as chlorhydric acid) for preparing chitosans [20-21]. Another strategy to improve the efficiency of chitosans is their low exploited combination with bentonites. The use of bentonites can improve the size and the density of the formed flocs which can result in an increase of its flocculation rate and at the same time can promote the adsorption of organics [22-23]. For a given level of contaminants' removal, the use of bentonites can help to reduce the required dosage of chitosan and thus, the treatment costs.

The objective of this study was first, to evaluate the efficiency of different chitosan treatments for the removal of dissolved and colloidal materials by the DAF process and second, to predict the efficiency of these treatments and their flocculation behaviour using the Focused Beam Reflectance Measurement technique (FBRM). Apart from the efficiency of native chitosans, the possible efficiency improvement on using chitosan quaternary derivatives or by a combined addition of the native chitosans with anionic bentonite microparticles were also assessed.

\section{MATERIALS AND METHODS}

\subsection{Materials}

Process water. Process water samples were obtained from a DAF unit at Holmen Paper Madrid mill, producing newsprint from $100 \%$ recovered paper. This mill has a highly closed water circuit with three water loops, each one equipped with a DAF unit for the internal treatment of the process waters of the loop. The samples were taken from the inlet of the DAF unit located in water loop 2, which include the process waters from postflotation, bleaching and thickening stages. The characterization of the process waters is shown in Table 1. Most of the contaminants, especially organic ones, are soluble: the dissolved COD is almost $83 \%$ of total COD and the suspended solids content is only around half of total solids. According to FBRM measurements, the mean chord size of 
the particles is $10.4 \mu \mathrm{m}$ and $87.0 \%$ of them are smaller than $20 \mu \mathrm{m}$. All trials and analyses were carried out within five days after taking the samples and the process water was always kept stored at $4^{\circ} \mathrm{C}$ before use to avoid their degradation.

Chemicals. Four chitosan products were tested; two native chitosans and two quaternary derivatives and their main characteristics are shown in Table 2. The two native chitosans have a very similar deacetylation degree and cationic charge density (CCD), but differ in their molecular weights; one has a medium molecular weight (Ch.MMW) and the other has a low molecular weight (Ch.LMW). They were both supplied by Sigma-Aldrich Co. The two quaternary derivatives (Quat.5 and Quat.10) were prepared from the low molecular weigth chitosan (Ch.LMW) using N-(3-chloro-2-hydroxypropyl) trimethylammonium chloride (Quat-188) as the quaternizing agent. They were prepared following the method described in [16] and two weight ratios chitosan:Quat-188 were used; one is 1:5 for Quat.5 and the other is 1:10 for Quat.10, in order to obtain two different quaternization degrees (Table 2). Anionic bentonite microparticles (Hydrocol ${ }^{\circledR}$ OT) were supplied by Ciba Specialty Chemicals (Switzerland) and were tested together with the native chitosans. The bentonite (B) is a montmorillonite sodium salt with a specific area of about $700-800 \mathrm{~m}^{2} / \mathrm{g}$ and a slight anionic charge $(0.235 \mathrm{meq} / \mathrm{g})$. According to FBRM measurements (described next), the median chord size of the bentonite is $17.5 \mu \mathrm{m}$; around $25 \%$ of the particles are lower than $10 \mu \mathrm{m}, 60 \%$ of the particles are lower than 20 $\mu \mathrm{m}, 80 \%$ are lower than $30 \mu \mathrm{m}$ and more than $95 \%$ are lower than $50 \mu \mathrm{m}$.

Chitosan products, both native chitosans and quaternary derivatives, were tested using dosages from 25 to $250 \mathrm{mg} / \mathrm{L}$. According to the results obtained in previous studies [2324], the bentonite was added in a fixed ratio chitosan:bentonite of $1: 2$ (wt./wt.) in dual systems.

\subsection{Methodology}

Dissolved air flotation tests (DAF tests). They were carried out in a laboratory-cell model Flottatest FTH3 supplied by Orchidis Laboratories (France). The experimental protocol followed is shown in Figure 1. The different dosages of chitosans and bentonite were added from $1.0 \mathrm{wt} . \%$ stock solutions to a $1 \mathrm{~L}$ volume of the process water sample. After flocculation, $200 \mathrm{~mL}$ of tap water saturated with air at about 6.5 bar was added for the flotation. Ten minutes after the addition of the air saturated water, a sample of the clarified water was collected from the bottom. A number of blanks were also carried out without adding any chemical so as to consider the dilution of the samples due to the addition of air-saturated water during flotation $(20 \%)$ and the efficiency of DAF to remove contaminants without previous coagulation/flocculation. All the tests were carried out at room temperature $\left(\sim 20^{\circ} \mathrm{C}\right)$ by duplicate and the average error between replicates was always under $5 \%$.

The efficiency of the different chemical treatments applied was evaluated by measuring turbidity, total solids, chemical oxygen demand (COD), cationic demand, $\mathrm{pH}$, conductivity and silica (Figure 1). Turbidity was measured according to ISO 7027:2001 
with a LP 2000-11 nephelometer supplied by Hanna Instruments. The total solids were measured according to the Standard Method 2450 B [25]. COD was measured employing the Nanocolor ${ }^{\circledR}$ COD 1500 test method (Macherey-Nagel GmbH) and using a Thermo Aquamate UV-Vis spectrophotomether for the end point. Cationic demand was measured by colloidal titration using a Charge Analyzing System (CAS) supplied by AFG Analytic $\mathrm{GmbH}$ and using $0.001 \mathrm{~N}$ poly-diallyl-dimethyl-ammonium chlorides (PDADMAC) as titrant. Reactive silica was measured by flow injection analysis through the silicamolybdate or molybdenum blue colorimetric method using a FIA Compact Analyzer (MLE GmbH), according to DIN EN ISO 16264:2002. Finally, pH and conductivity of the samples were measured according to Standard Methods using a GLP$22 \mathrm{pH}-$ meter and a GLP-32 conductivity meter, both supplied by Crison Instruments, S.A. [25]. All measurements were also carried out by duplicate. To obtain the dissolved and colloidal fraction of the samples, they were centrifuged at $4128 \mathrm{rpm}(2000 \mathrm{~g})$ during 15 min using a Universal 16 centrifuge supplied by Hettich Zentrifugen GmbH.

FBRM tests. FBRM technique monitors in real-time the chord length distribution and the number of particles in a suspension. The data can be used to analyze the flocs properties and the flocculation mechanisms allowing the selection of both the best chemicals and the optimal chemical dosages [26]. FBRM technique has been previously used for the chemical optimization of the DAF treatments in papermaking processes [8-10, 27-29].

The measurements were performed using a M500L FBRM supplied by Mettler-Toledo (United States) at the same experimental conditions used in the DAF tests. First, sequential additions of the chitosan treatments were carried out. This procedure allowed the determination of the optimum dosages of the chitosans to obtain the maximum mean chord size of the flocs and the maximum number of destabilized DCM thus, acquiring a possible maximum efficiency in the DAF treatment. In these tests, the FBRM probe is submerged into $250 \mathrm{~mL}$ water being stirred at $180 \mathrm{rpm}$ and after $30 \mathrm{~s}$ of system stabilization, the chitosan is continuously added at sequential additions of $25 \mathrm{mg} / \mathrm{L}$ every 30 s while maintaining the stirring speed. Second, the flocculation behaviour with time was analyzed after the addition of a single dose of the chitosans. These dosages were selected according to the results of the study of the sequential additions of the chitosans and were the same as those tested in the DAF treatments for an effective comparison. In these tests, the probe is submerged into $250 \mathrm{~mL}$ water and after $30 \mathrm{~s}$ of system stabilization, the chitosans were added at a single dosage. After 90 s of the addition of the chitosan, the bentonite was added (when dual systems are used). Finally, the evolution of the system was monitored during 5 minutes. Stirring speed was maintained constant during the test at $180 \mathrm{rpm}$.

\section{RESULTS AND DISCUSSION}

\subsection{FLOCCULATION BEHAVIOUR STUDY}

The flocculation process was first studied to predict the effectiveness of the different chemicals for DCM removal by DAF where two different approaches were used. 


\subsubsection{Sequential additions of the coagulant}

Figure 2 shows the increase of the mean chord size when consecutive coagulant additions were used. Initially, the mean chord size is around $10 \mu \mathrm{m}$. The native chitosans increased the mean chord size up to a maximum of $34 \mu \mathrm{m}$ in the case of Ch.MMW and to $23 \mu \mathrm{m}$ in the case of Ch.LMW at dosages in the range 150-250 mg/L. The chitosan derivatives increased the mean chord size in a lower extent than does the Ch.LMW $(17-20 \mu \mathrm{m})$ and their maximum efficiency occurred at higher dosages than those dosages of the native chitosans (275-350 mg/L). In this case, Quat.5 was slightly more effective than Quat.10. When native chitosans were used in combination with the bentonite, a clear synergistic effect was observed. In this case, the mean chord size of the flocs increased to 70-85 $\mu \mathrm{m}$ which means two to four times higher than those obtained with native chitosans alone. In addition, the maximum efficiency was obtained at slightly lower dosages than those dosages of the native chitosans alone; $150-200 \mathrm{mg} / \mathrm{L}$ versus $200-250 \mathrm{mg} / \mathrm{L}$.

The evolution of total number of counts gives also valuable information about the efficiency of the different coagulants (Figure 3). Initially, the total number of counts of the process water was around $2200 \pm 100(\# / \mathrm{s})$. When successive dosages of coagulants are added to the sample, it is observed a clear increase in the total number of counts. The reason is that the coagulant destabilizes the particles with a size lower than $1 \mu \mathrm{m}$ (previously not detected by FBRM) and increases their particle size enough to be detected by the device $(>1 \mu \mathrm{m})$. A higher increase in the counts number means more destabilized DCM. However, this increase must be analyzed together with the mean chord size of the resulting flocs to determine whether this size is large enough to be efficiently removed by DAF.

Native chitosans seem to be the most efficient coagulants as an effective increase in the total number of counts have been registered (up to $11000-13000 \mathrm{\#} / \mathrm{s}$ ) at the lowest dosages, i.e. $125 \mathrm{mg} / \mathrm{L}$. Although quaternary derivatives increased the total number of counts to a higher extent (up to $11,000-16,000 \mathrm{\# /s}$ ), considerably higher dosages (200$250 \mathrm{mg} / \mathrm{L}$ ) were necessary. The dual systems chitosan-bentonite produced the lowest increase in the total number of counts although they were able to increase the total number of counts up to approximately $7000 \mathrm{\#} / \mathrm{s}$ at only around $100 \mathrm{mg} / \mathrm{L}$. At higher dosages, an important decrease in the number of counts occurred thus indicating that the previously destabilized particles are effectively aggregated to larger flocs (as demonstrated by the increase in the mean chord size at dosages higher than $100 \mathrm{mg} / \mathrm{L}$ ). The increase in the mean chord size of the flocs formed by dual systems is considerably higher than those increases observed for single systems, therefore indicating that the microflocs obtained after the destabilization of DCM by chitosan can be effectively agglomerated to macroflocs by bentonite addition.

However, the other treatments especially quaternary derivatives are not effective in the aggregation of the previously destabilized particles. The case of native chitosans is intermediate. They produced an intermediate destabilization of DCM and an intermediate agglomeration of the previously destabilized DCM. After reaching the maximum total number of counts, there is a higher decrease in the number of particles (which means 
aggregation) with Ch.MMW than with Ch.LMW which could indicate that Ch.MMW is slightly more efficient than Ch.LMW. However, the number of particles previously destabilized by Ch.LMW is higher (around 13000 \#/s versus $11000 \# / s$ ) which could be attributed to the lower increase in the mean chord size of the flocs. Therefore, it is difficult to select which native chitosan would be the most efficient in DAF treatments.

The analysis of the evolution of the number of counts between 1 and $10 \mu \mathrm{m}$ (data not shown) have demonstrated the destabilization of DCM particles smaller than $1 \mu \mathrm{m}$. The trend in the number of counts lying between 1 and $10 \mu \mathrm{m}$ is almost the same as that observed for the increase in the total number of counts evolution. Therefore, this demonstrates that the increase in total number of counts has been mainly due to the increase in the number of particles in this small size range.

\subsubsection{A single addition of the coagulant}

Comparing the mean chord size and the number of counts statistics for the different treatment systems and at the same dosages and conditions as those used for DAF tests, different behaviors are obtained. Figure 4 presents the mean chord size of the aggregates depending on the coagulant dosages. On using single systems, the most efficient products in increasing mean chord size are native chitosans where Ch.MMW is more efficient than Ch.LMW. For both chitosans, the mean chord size of the particles increases at increased dosages observing a maximum value at around $150-200 \mathrm{mg} / \mathrm{L}$ which could be considered as the optimal dosage. At higher dosages of chitosan (i.e. $250 \mathrm{mg} / \mathrm{L}$ ), the mean chord size decreases because the isoelectric point is reached and flocs destabilization takes place. At these dosages, the cationic demand of treated waters is $0-0.03 \mathrm{meq} / \mathrm{L}$. When using chitosan derivatives, Quat.5 and Quat.10, the flocs size increase is smaller than those obtained with the original chitosan (Ch.LMW). In this case, the mean chord size also increases with the dosage, but no deterioration of the flocs size at the highest dosages has been observed. This is because the cationic demand of the waters treated with $250 \mathrm{mg} / \mathrm{L}$ of quaternary derivatives was still far from the isoelectric point $(0.48-0.51 \mathrm{meq} / \mathrm{L})$. Among the quaternary derivatives, Quat.5 seems to be slightly better than Quat.10, especially at dosages higher than $150 \mathrm{mg} / \mathrm{L}$.

When bentonite is added together with the native chitosans (1:2 wt. ratio), their efficiency in increasing the size of the aggregates is clearly enhanced especially at intermediate dosages (around $100 \mathrm{mg} / \mathrm{L}$ ). With this dual system it is possible to obtain considerably larger flocs than with the other treatments (mean chord size of 80-100 $\mu \mathrm{m}$ ). At the same time, the dosage can be reduced to the half, $75-100 \mathrm{mg} / \mathrm{L}$ can be considered as the optimal dosages. When bentonite is added, Ch.LMW is slightly more efficient than Ch.MMW. This behaviour of the Ch.LMW could be explained to fast interaction of chitosan molecules with DCM and formation first of small aggregates with cationic charge patches that further interact with anionic sides of other aggregates. At higher chitosan dosages, this phenomenon is counterbalanced by the cationic charge excess which leads to high dispersion rate of formed flocs (see also Figure 2). 
The increase in total number of counts with time has been also analyzed (Figure 5). The total number of counts increases with time for both the native and quaternized chitosans. This is due to the destabilization of the dissolved and colloidal material which is initially below the detection limit of FBRM device, but reaches a detectable size after aggregation $(>1 \mu \mathrm{m})$. Up to dosages between $50 \mathrm{mg} / \mathrm{L}$ to $150 \mathrm{mg} / \mathrm{L}$ and even at $200 \mathrm{mg} / \mathrm{L}$ for quaternized chitosans, there is an important increase in the total number of counts. However, at the highest dosages, the number of counts generally decreased due to the aggregation of the previously destabilized DCM and thus, the mean chord size increased, as can be seen in Figure 4. This could be a very positive effect due to the use of chitosan products as they have the advantage of coagulating small particles [30] which cannot be separated otherwise by DAF system. Although flotation is generally promoted by large flocs (high mean chord size), but in some cases a low mean chord size with a higher number of counts indicate that DCM has been destabilized and aggregated forming small flocs that can be also removed subsequently by flotation [8, 28-29]. Nevertheless, there is still a need to further increase the size of the flocs to be efficiently removed by DAF. When bentonites are added together with the native chitosans, there is no clear trend and it always depends on the data obtained for the mean chord size. Generally, the total number of counts remains similar to that of the process waters while the mean chord size is increasing largely at low and intermediate dosages. However, at the highest dosages, when the mean chord size starts decreasing, there is a parallel increase in the total number of counts. Therefore, this increase confirms a slight higher efficiency of Ch.LMW than the Ch.MMW in increasing the floc size.

\subsection{DISSOLVED AIR FLOTATION TESTS}

Effect of coagulants on turbidity. Turbidity of the waters was not significantly reduced by DAF when chemicals were not used. The removal of turbidity observed in the blank samples from 2400 NTU to 1840 NTU (22.9\% removal), is justified by the dilution of the waters caused by the addition of $20 \%$ saturated air-tap water. This means that in an industrial DAF unit where the clarified water is the stream saturated with air, the removal of turbidity without any chemical treatment would be almost negligible, which is the case in the paper mill from which the samples were taken. Although around $50 \%$ of total solids are suspended solids, the size of these suspended solids is very small. According to FBRM measurements, mean chord size of particles $(1-1000 \mu \mathrm{m})$ is around $10 \mu \mathrm{m}$ and median is $7 \mu \mathrm{m}$, which is a very small size to be removed by DAF and especially for a lab DAF unit with a reduced hydrodynamic efficiency compared to the industrial DAF units.

Most efficient products in removing the turbidity of clarified waters are the native chitosans (Figure 6a), which reduced turbidity to 10-12 NTU (99.3-99.4\% removal referred to the blank values) at the highest dosages. However, intermediate dosages such as $150 \mathrm{mg} / \mathrm{L}$ are high enough to obtain very high removal efficiencies (95.6-98.6\%) with turbidity of the treated waters of 25-85 NTU. Differences between Ch.MMW and Ch.LMW are minor, but Ch.LMW is slightly more efficient than Ch.MMW despite that FBRM measurements indicated that Ch.MMW is able to produce larger flocs with similar destabilization of DCM. Previous studies showed that generally high molecular weight 
chitosans are more efficient than low molecular weight ones [20,31], which is not the case in this study according to the results obtained.

Quaternary chitosans are clearly less efficient in removing turbidity than native chitosans. Quat.5 is more efficient than Quat.10 thus, confirming the FBRM observations. With these products, a maximum removal of $94 \%$ (around 110 NTU of residual turbidity) was achieved at the highest dosage tested $(250 \mathrm{mg} / \mathrm{L})$. However, intermediate dosages of these products such as $150 \mathrm{mg} / \mathrm{L}$, can only achieve turbidity removals in the $70-85 \%$ range. For a similar turbidity removal, quaternized chitosans require around double the dosage than that required for native chitosans. This is in agreement with the fact that quaternary chitosans have around half of the cationic charge of the native chitosans and can be an indication that charge neutralization flocculation mechanism is taking place to a large extent.

The addition of bentonite improved significantly the turbidity removal obtained by native chitosans especially at the lowest dosages of chitosan. The use of bentonite can slightly improve the removal obtained by the native chitosans up to $99.7 \%$ (residual turbidity of 5 NTU). However, the most important enhancement occurs at the lowest dosages. For example, at $50 \mathrm{mg} / \mathrm{L}$, native chitosans reduced turbidity to $750-800 \mathrm{NTU}(<60 \%$ removal) while the combination of chitosans with bentonite reduced turbidity to 200-320 NTU (80-90\% removal) which could be a sufficient turbidity removal in industrial applications. Furthermore, the use of chitosan dosage of $75 \mathrm{mg} / \mathrm{L}$ with $150 \mathrm{mg} / \mathrm{L}$ bentonite is able to reduce the turbidity of clarified waters around $97-99 \%$ (residual turbidity of 25-50 NTU). To achieve similar results, however, the necessary dosages of native chitosans would be $150-200 \mathrm{mg} / \mathrm{L}$.

The same trends have been observed for dissolved turbidity (Figure 6b). Most efficient products are Ch.MMW and Ch.LMW both with and without bentonite addition. Maximum removal efficiencies of $94-98 \%$ referred to the blank are obtained at the highest dosages while with intermediate dosages, $90 \%$ removal efficiencies can be also obtained. Like the FBRM study, the quaternary chitosans were clearly of lower efficiency than the native chitosans. Again Quat.5 is more efficient than Quat.10 while Quat.5 can obtain a maximum removal of dissolved turbidity of around $95 \%$ (residual turbidity of 4 NTU), maximum removal efficiency with Quat.10 is 75\% (residual turbidity of 20 NTU).

Effect of coagulants on total solids. As expected, the total solids followed similar trends to turbidity measurements. The most efficient treatments in removing total solids from process water (Figure 7) are native chitosans followed by their combination with bentonites and finally, quaternized derivatives. With Ch.MMW and Ch.LMW, total solids are reduced from around $3500 \mathrm{mg} / \mathrm{L}$ (blank value) to $2500-2600 \mathrm{mg} / \mathrm{L}$ which means $25-30 \%$ total solids removal. For these treatments, total solids removal is not improved significantly at higher dosages than $75-100 \mathrm{mg} / \mathrm{L}$. Process water have 5500 $\mathrm{mg} / \mathrm{L}$ of total solids: around $2800 \mathrm{mg} / \mathrm{L}$ of suspended solids and $2700 \mathrm{mg} / \mathrm{L}$ of dissolved solids. DAF treatments with native chitosans are able to eliminate almost all suspended solids (as seen with the turbidity of clarified waters after treatment) and around 100-200 $\mathrm{mg} / \mathrm{L}$ of dissolved solids (4-8\% removal of dissolved solids). Quaternary chitosans 
efficiency in removing total solids was lower than the native products. With the quaternized chitosans, maximum removal of total solids is $15-18 \%$ (residual $2900-3000$ $\mathrm{mg} / \mathrm{L}$ total solids) even at the highest dosage tested. This means that still 100-200 $\mathrm{mg} / \mathrm{L}$ suspended solids and all the dissolved solids have not been removed. As it was observed with turbidity measurements, Quat.5 is slightly more efficient than Quat.10, but the differences are minimal. Contrary to native chitosans, the removal of total solids is continuously increased with higher dosages where the best results being obtained at the highest dosage $(250 \mathrm{mg} / \mathrm{L})$.

The use of bentonite in combination with the native chitosans has a minor effect on total solids of clarified waters and its effect varies depending on the chitosan considered. In the case of Ch.LMW, the addition of bentonite slightly improved its efficiency while in the case of Ch.MMW, this addition slightly impaired its efficiency. Although the addition of bentonite was very effective in removing turbidity of clarified waters, its effect on total solids is minor probably as dissolved solids are the main part of total solids and they are only slightly removed by the treatments. In addition, it could be possible that some of the bentonite added, due to its small size and high density, could not be aggregated or removed efficiently during the flotation process and thus, contributing to the total solids of clarified waters. This could justify that suspended solids removal (measured through turbidity) could be improved by bentonite addition but total solids removal could be similar with or without bentonite addition.

Effect of coagulants on COD. The COD is a very important parameter in terms of process water contamination in papermaking. However, opposite to the turbidity or suspended solids which are generally removed in a large extent in the dissolved air flotation units (80-99\%), COD removal is almost negligible in most of the cases. Only if an adequate chemistry is selected, DAF can also help to purge some organics from the water systems minimizing the accumulation of the DCM in water circuits [1].

The maximum COD removal efficiencies are in the $20-25 \%$ range as compared to the blank value (around $1900 \mathrm{mg} / \mathrm{L}$ ), with residual COD values varying from 1400 to 1500 $\mathrm{mg} / \mathrm{L}$ (Figure 8). The most efficient products are Ch.MMW and Ch.LMW. As soluble COD of the process water is around $1900 \mathrm{mg} / \mathrm{L}$ (similar value to that of the blank), these treatments are able to remove $20-25 \%$ of dissolved COD which is an important achievement. As with other analytical parameters, the efficiency of quaternized chitosans is lower than other Ch.MMW and Ch.LMW-based treatments, however, at the highest dosages $(200-250 \mathrm{mg} / \mathrm{L}$ ), the efficiency in COD removal can achieve 20\% (around 1500 $\mathrm{mg} / \mathrm{L}$ residual COD). Although the maximum removal efficiencies are similar for both types of chitosans, $25 \%$ for native chitosans versus $20 \%$ for quaternary derivatives, there is an important difference: native chitosans achieve these maximum COD removal efficiencies at very low dosages $(50-75 \mathrm{mg} / \mathrm{L})$ while the maximum removal efficiency for quaternary derivatives is only achieved at dosages as high as $250 \mathrm{mg} / \mathrm{L}$.

The use of bentonite in conjunction with the chitosan improved COD removal, especially at the smallest dosage of chitosan $(50 \mathrm{mg} / \mathrm{L})$, for both Ch.MMW and Ch.LMW. At this dosage, the use of bentonite improves COD removal from $14 \%$ to $19 \%$ for Ch. MMW 
and from $19 \%$ to $23 \%$ for Ch. LMW. However, the differences between using bentonite and not are lower and lower and lower at increased chitosan dosages. Although some authors argue that the preparation of native chitosans with acetic acid could increase the organic content of the treated water [20-21] and for this reason it is sometimes preferably to use acids such as chlorhydric acid, this effect has not been observed as relevant in this study probably due to the high COD levels found in this water.

Effect of coagulants on cationic demand. Along with the turbidity or COD, charge measurement is generally accepted as one of the most important indicators of the amount of detrimental substances in papermaking although not all interfering substances are anionic [32].

As shown in Figure 9 the cationic demand of waters is efficiently reduced by the different chitosan-based treatments. The cationic demand is decreased in parallel with the chitosan dosage and the cationic demand values come very close to zero at the highest dosage $(250 \mathrm{mg} / \mathrm{L})$ especially for Ch.MMW- and Ch.LMW-based treatments. With these treatments, the final cationic demand is around $0.04-0.10 \mathrm{meq} / \mathrm{L}(90-96 \%$ removal) and is even zero when only Ch.MMW is added. The effect of bentonite on cationic demand is producing only a small increase compared to the native chitosans based treatment which is in agreement with its small anionic charge. On the other hand, the quaternized derivatives reduced the cationic demand $48-52 \%(0.48-0.52 \mathrm{meq} / \mathrm{L}$ residual cationic demand). These observations are in agreement with the charge densities of the products. Ch.MMW and Ch.LMW have charge densities of 5.75 and $5.44 \mathrm{meq} / \mathrm{g}$, respectively, while the quaternised products is around half, $2.27 \mathrm{meq} / \mathrm{g}$ in the case of Quat.5 and 2.11 in the case of Quat.10.

It is observed from Figure 9 that the differences in neutralization efficiency between native chitosans based treatments and quaternary chitosans treatments is varying with the dosage. At the lowest dosages $(50-75 \mathrm{mg} / \mathrm{L})$, quaternary chitosans reduced more efficiently the charge than treatments based on native chitosans. At intermediate dosage $(100 \mathrm{mg} / \mathrm{L})$, the efficiency becomes similar, and at the highest dosages $(\geq 150 \mathrm{mg} / \mathrm{L})$, the native chitosans based treatments become more efficient in reducing the cationic demand of waters than quaternary chitosans; the higher the dosage the higher difference between the cationic demand of the treatments based on native and quaternary chitosans.

The explanation is related to the effect of $\mathrm{pH}$ on the charge density of chitosans. While quaternary chitosans have an almost permanent positive charge on the polymer backbone, native chitosans have a charge density dependent on $\mathrm{pH}$. Native chitosans must be dissolved either in acetic acid or hydrochloric acid thus, in acidic solutions where the amino groups in chitosans are protonated resulting in a high charge density and solubility of the native chitosans. However, at neutral to alkaline $\mathrm{pHs}$, chitosan loses its charge and precipitate from solution [33]. As shown in Figure 10, the cationic charge of native chitosans is sharply decreased at $\mathrm{pHs}$ higher than 6.5 and become almost zero at a $\mathrm{pH}$ 7.5-8.0. On the contrary, cationic charge of quaternary derivatives is almost constant from $\mathrm{pH} 4$ to $\mathrm{pH} 7$ and decreases only slightly at alkaline $\mathrm{pHs}$ (outside the experimental 
$\mathrm{pH}$ range). Even at high alkaline $\mathrm{pHs}$ as 10 , quaternary derivatives still maintain their cationicity and their cationic charge is only $30-40 \%$ lower than this at $\mathrm{pH} 4$.

$\mathrm{pH}$ of the blank (DAF treatment without any chemical) is 7.6 and at this $\mathrm{pH}$ theoretically the charge density of the quaternary chitosans would be higher than the native chitosans, and this result was observed at the lowest dosages of chitosans. However, as the dosage of native chitosans is increased (due to the acidic nature of the stock solution), the $\mathrm{pH}$ of the treated waters is continuously reduced. Although this decrease is not very noteworthy (0.6-0.8 $\mathrm{pH}$ units), this decrease is high enough for an important increase of the cationic charge of the native chitosans. At the highest dosage of native chitosans, $\mathrm{pH}$ of the treated waters can be reduced to around 6.8. Considering that the air-saturated water (tap water) added after flocculation having a $\mathrm{pH}$ around 7.6, the flocculation $\mathrm{pH}$ (before airsaturated water addition) could be even lower, around 6.6. At this $\mathrm{pH}$, the charge density of native chitosans can be around double that of quaternary derivatives. This is the reason why the differences between quaternary derivatives and native chitosan based treatments on cationic demand are higher at the highest dosages. Furthermore, results from Figure 10 shows that the charge density of Ch.LMW is higher than Ch.MMW at $\mathrm{pH}>6$ which could explain why Ch.LMW could be more efficient than Ch.MMW.

The two main flocculation mechanisms of chitosans are charge neutralization and bridging formation and a combination of them usually occurs. However, in the case of native chitosans, due to its charge density dependence on $\mathrm{pH}$, the importance of each has varied depending on the dosage. At the lowest dosages, the $\mathrm{pH}$ of waters is still high and the charge density of the chitosan is low where bridging formation is the main flocculation mechanism. At the highest dosages, the $\mathrm{pH}$ is low enough for having a high charge density and charge neutralization is the main flocculation mechanism.

Effect of coagulants on $\mathbf{p H}$ and conductivity. Regarding $\mathrm{pH}$ of the clarified waters, there are also slight differences between the native chitosans (with or without bentonite) and the quaternary derivatives. In the case of quaternary derivatives, $\mathrm{pH}$ is maintained almost constant even at the highest dosages tested. On the other hand, native chitosans reduced the $\mathrm{pH}$ of waters; this decrease being higher at higher dosages of chitosan. At the highest dosages of these chitosans, the $\mathrm{pH}$ reduction can be around 0.6-0.8 $\mathrm{pH}$ units. As commented before, the explanation of this behaviour is related to the preparation method of the different chitosan products; native chitosans are prepared on acetic acid $0.1 \mathrm{M}(\mathrm{pH}$ around 4.0), and quaternary chitosans are directly prepared in distilled water therefore, their addition has no significant effect on the $\mathrm{pH}$ of clarified waters. Traditional treatments based on aluminum or iron salts usually produce higher $\mathrm{pH}$ reductions as they consume part of the alkalinity of the waters to form the active species. Using organic coagulants such as chitosans, this can be minimized or even completely removed.

Conductivity of the waters only slightly increased with the different treatments. In the case of native chitosans with and without bentonite addition, the maximum increase was around $0.2 \mathrm{mS} / \mathrm{cm}$ (at $250 \mathrm{mg} / \mathrm{L}$ ) as referred to the blank value. This increase is mainly due to the use of acetic acid in their preparation (stock solutions has around $0.4 \mathrm{mS} / \mathrm{cm}$ conductivity). Quaternized chitosans prepared in distilled water increased the 
conductivity only $0.05-0.1 \mathrm{mS} / \mathrm{cm}$ at the highest dosage tested $(250 \mathrm{mg} / \mathrm{L})$. One of the advantages of using organic versus inorganic coagulants as aluminum or ferric salts is the lower or even negligible conductivity increase of the treated waters. As inorganic DCM is not removed in conventional internal water treatments used in papermaking such as DAF units, the lower the increase of conductivity in the treated waters, the lower accumulation of inorganic DCM in water circuits [1].

Effect of coagulants on silica. DAF units are usually inefficient in removing inorganic compounds. However, in the analyzed paper mill, there is a high silica content in the water circuits varying in the range $150-250 \mathrm{mg} / \mathrm{L}\left(\mathrm{as} \mathrm{SiO}_{2}\right)$ depending on the water loop considered and its removal could be of interest due to future environmental discharge regulations. The results obtained indicated that only minor silica removals can be obtained with these treatments; always lower than 5-10\%. Efficiency differences among the different treatments cannot be clearly assessed as these differences are very close to the experimental error of the silica measurement method. Although coagulation has been used in the literature to remove silica from papermaking waters, significant removals can be achieved only at high pHs and dosages [34-36] which is not the present case.

\section{CONCLUSIONS}

Native chitosans, Ch.MMW and Ch.LMW, have demonstrated to be efficient at intermediate dosages while Ch.LMW being more efficient than Ch.MMW. This is probably due to the higher charge density of Ch.LMW at a $\mathrm{pH}>6$. At $100 \mathrm{mg} / \mathrm{L}$ dosage, they resulted in the following removal efficiencies as referred to the blank: $88-90 \%$ turbidity (residual turbidity of 185-215 NTU), 60-75\% dissolved turbidity (residual dissolved turbidity of 20-30 NTU), 24-27\% total solids (residual $2550-2700 \mathrm{mg} / \mathrm{L}$ total solids) and 22\% COD (residual 1455-1465 mg/L COD). Although the main disadvantage of commercial chitosan products is their insolubility at neutral and alkaline pHs, both chitosans have demonstrated to be efficient for treating the process waters even at the initial $\mathrm{pH}$ of 7.6. The high cost of chitosan could be compensated by the lower dosages necessary to obtain the same results as those obtained with the conventional products.

When native chitosans are tested in dual systems with bentonite, even $50 \mathrm{mg} / \mathrm{L}$ of chitosan added together with $100 \mathrm{mg} / \mathrm{L}$ bentonite is enough to achieve high removals of contaminants: $83-89 \%$ turbidity (residual turbidity of $210-320$ NTU), $68-71 \%$ dissolved turbidity (residual dissolved turbidity of 22-24 NTU), 18-22\% total solids (residual total solids of $2750-2900 \mathrm{mg} / \mathrm{L})$ and $19-23 \%$ COD (1440-1525 mg/L). The low cost of the bentonite compared to chitosan would definitely reduce the cost of the treatment and for the same level of efficiency, the required dosage of chitosan is roughly half the dosage necessary if bentonites are not added $(50 \mathrm{mg} / \mathrm{L}$ versus $100 \mathrm{mg} / \mathrm{L})$. Again, the highest removal efficiency was obtained with the low molecular weight chitosan.

Quaternary derivatives obtained lower efficiency than the base chitosan used (Ch.LMW). The main reason for this is the lower charge density of the quaternary derivatives compared to the native chitosans at the operational conditions. Although the charge density of the native chitosans starts decreasing at $\mathrm{pH} 6.5$ and becomes zero at around $\mathrm{pH}$ 
7.5-8, the charge density of native chitosans is still higher than these of quaternary derivatives especially if we consider than the addition of the acidic solution of native chitosans reduced the $\mathrm{pH}$ of the treated waters in parallel. The $\mathrm{pH}$ of the treated waters was reduced from a $\mathrm{pH}$ of 7.6 (blank) to around $\mathrm{pH} 6.8$ at the highest dosages of the native chitosans while the $\mathrm{pH}$ of the treated waters was around 7.7-7.8 independent of the dosages of the quaternized chitosans. In this application, the $\mathrm{pH}$ is just in the limit where the native chitosans can still be applied and there is no need for quaternary derivatives. The higher quaternization degree, the lower was the efficiency of the derivatives. In all the cases, Quat.5 was more efficient than Quat.10 probably by their slightly higher charge density $(2.27 \mathrm{meq} / \mathrm{g}$ versus $2.11 \mathrm{meq} / \mathrm{g})$.

The FBRM technique has proven to be a rapid and accurate method in providing information about polyelectrolyte-induced aggregation. The smallest chemical dose that efficiently aggregated DCM and also the dosages range to be tested in DAF tests, including the preliminary optimal dosage, were determined by FBRM technique. The data provided by FBRM are in agreement with the efficiency of chitosan and chitosanbentonite systems to reduce turbidity, total suspended solids content and COD of the treated water in DAF tests. The FBRM predicted a higher efficiency of dual systems compared to single systems, a higher efficiency of these native chitosans compared to the quaternized derivatives and the higher efficiency of Quat.5 compared to Quat.10. The prediction of a higher efficiency of Ch.LMW compared to Ch.MMW, however, was not as clear as with the other treatments.

\section{ACKNOWLEDGEMENTS}

The authors wish to acknowledge the financial support of the Community of Madrid through "PROLIPAPEL II" (P2009/AMB-1480). They also want to acknowledge the doctoral grant to Isabel Latour (AP2009-4197) by the Spanish Ministry of Education and Science and the grant to Raluca Nicu by the project PERFORM-ERA "Postdoctoral Performance for Integration in the European Research Area" (ID-57649) and the project EURODOC "Doctoral Scholarships for research performance at European level" project (ID-59410)" where both are financed by the European Social Fund and the Romanian Government. Finally, we would like to thank Holmen Paper Madrid for its collaboration during this study.

\section{LITERATURE}

[1] R. Miranda, A. Blanco, C. Negro, Accumulation of dissolved and colloidal material in papermaking - Application to simulation, Chem. Eng. J. 148 (2009) 385-393.

[2] G. Bourgogne, J.E. Laine, A review of the effects of reduced water consumption on the wet end of the paper machine and the quality of water, Pap. Puu-Pap. Timb. 83 (2001) 190-203.

[3] A. Blanco, C. Negro, C. Monte, H. Fuente, J. Tijero, Overview of two major deposit problems in recycling: slime and stickies. Part II: stickies problems in recycling, Prog. Pap. Recycl. 11 (2002) 2637.

[4] H.K. Lee, C.H. Ham, S.G. Lee, Influence of papermaking system closure on paper properties, Tappi J. 5 (2006) 27-31.

[5] Y. Ben, G. Dorris, G. Hill, J. Allen, Contaminant removal from deinking process water. Part I: Mill benchmarking, Pulp Pap. Can. 104 (2003) 42-48. 
[6] A.H. Basta, H. Zhan, B. He, X. Wang, G. Zao, J. Chen, Cleaning efficiency of process water in newsprint mill, Prog. Pap. Recycl. 13 (2004) 13-22.

[7] A. Roring, E. Wackerberg, Characterization of deinking white water - Influence on flotation and bleaching efficiency, Pulp Pap. Can. 98 (1997) 17-21.

[8] R. Miranda, A. Blanco, E. Fuente, C. Negro, Separation of contaminants from deinking process water by dissolved air flotation: effect of flocculant charge density, Sep. Sci. Technol. 43 (2008) $3732-3754$.

[9] R. Miranda, C. Negro, A. Blanco, Internal treatment of process waters in paper production by dissolved air flotation with newly developed chemicals. 1. Laboratory tests, Ind. Eng. Chem. Res. 48 (2009) 2199-2205.

[10] R. Miranda, C. Negro, A. Blanco, Internal treatment of process waters in paper production by dissolved air flotation with newly developed chemicals. 2. Field trials, Ind. Eng. Chem. Res. 48 (2009) 3672-3677.

[11] S.A. Ali, S. Pal, R.P. Singh, Flocculation performance of modified chitosan in an aqueous suspension, J. Appl. Polym. Sci. 118 (2010) 2592-2600.

[12] T. Chatterjee, S. Chatterjee, S.H. Woo, Enhanced coagulation of bentonite particles in water by a modified chitosan biopolymer, Chem. Eng. J. 148 (2009) 414-419.

[13] S. Bratskaya, S. Schwarz, D. Chervonetsky, Comparative study of humic acids flocculation with chitosan hydrochloride and chitosan glutamate, Water Res. 38 (2004) 2955-2961.

[14] D. Belosinschi, E. Bobu. Effects of coagulants on the DCS'accumulation in process water of papermaking, Env. Eng. Manage. J. 7 (2008) 269-277.

[15] E. Bobu, R. Nicu, J. Desbriers, Chitosan as cationic polyelectrolyte in wet-end papermaking systems, Cellul. Chem. Technol. 45 (2011) 105-111.

[16] W. Sajomsang, S. Tantayanon, V. Tangpasuthadol, W.H. Daly, Quaternization of N-aryl chitosan derivatives: synthesis, characterization, and antibacterial activity, Carbohydr. Res. 344 (2009) 25022511.

[17] W. Sajomsang, Synthetic methods and applications of chitosan containing pyridylmethyl moiety and its quaternized derivatives: A review, Carbohydr. Polym. 80 (2010) 631-647.

[18] H. Li, Y. Du, X. Wu, H. Zhan, Effect of molecular weight and degree of substitution of quaternary chitosan on its adsorption and flocculation properties for potential retention-aids in alkaline papermaking. Colloids Surf., A 242 (2004) 1-8.

[19] J.-P. Wang, W.-Z. Chen, S.-J. Yuan, G.-P. Sheng, H.-Q. Yu, Synthesis and characterization of a novel cationic chitosan-based flocculant with a higher water-solubility for pulp mill wastewater treatment, Water Res. 43 (2009) 5267-5275.

[20] F. Renault, B. Sancey, P.-M. Badot, G. Crini, Chitosan for coagulation/flocculation processes An eco-friendly approach, Eur. Polym. J. 45 (2009) 1337-1348.

[21] C. Huang, S. Chen, J.R. Pan, Optimal condition for modification of chitosan: a biopolymer for coagulation of colloidal particles, Water Res. 34 (2000) 1057-1062.

[22] Z.-S. Cai, C.-S. Yang, X.-M. Zhu, Preparation of quaternized carboxymethyl chitosan and its capacity to flocculate COD from printing wastewater. J. Appl. Polym. Sci. 118 (2010) 299-305.

[23] R. Nicu, R. Miranda, E. Bobu, A. Blanco, Improved efficiency of chitosans with bentonites for the retention and drainage of pulp suspensions. Submittted to Bioresources (2013).

[24] S. Syafalni, I. Abustan, S.F. Zakaria, M.H. Zawawi, R.A. Rahim. Raw water treatment using bentonite-chitosan as coagulant. Wat. Sci. Tec. Wat. Supl. 12 (2012), 480-488.

[25] Standard Methods for the Examination of Water and Wastewater, American Public Health Association (APHA), American Water Works Association (AWWA), Water Environment Federation (WEF), $21^{\text {st }}$ ed., United States, 2005.

[26] A. Blanco, E. Fuente, C. Negro, J. Tijero, Flocculation monitoring: Focused beam reflectance measurement as a measurement tool, Can. J. Chem. Eng. 80 (2002) 734-740.

[27] C. Negro, A. Blanco, V. Saarimaa, J. Tijero, Optimization of pitch removal by dissolved air flotation in a Eucalyptus kraft mill, Sep. Sci. Technol. 40 (2005) 1129-1143. 
[28] V. Saarimaa, A. Sundberg, B. Holmbom, A. Blanco, E. Fuente, C. Negro, Monitoring of dissolved air flotation by focused beam reflectance measurement, Ind. Eng. Chem. Res. 45 (2006) 7256-7263.

[29] V. Saarimaa, A. Sundberg, B.H. Holmbom, A. Blanco, C. Negro, E. Fuente, Purification of peroxide-bleached TMP water by dissolved air flotation, Tappi J. 5 (2006), 15-21.

[30] R. Nicu, E. Bobu, R. Miranda, A. Blanco, Flocculation efficiency of chitosan for papermaking applications, Bioresources 8 (2013) 768-784.

[31] J. Roussy, M. van Vooren, B.A. Dempsey, E. Guibal, Influence of chitosan characteristics on the coagulation and the flocculation of bentonite suspensions, Water Res. 39 (2005) 3247-3258.

[32] J. Liu, Charge of papermaking system - what role it plays in paper mills, Pap. Technol. 42 (2001) 29-31.

[33] R. Rojas-Reyna, S. Schwarz, G. Heinrich, G. Petzold, S. Schütze, J. Bohrisch, Flocculation efficiency of modified water soluble chitosan versus commonly used commercial polyelectrolytes, Carbohydr. Polym. 81 (2010) 317-322.

[34] T.S. Huuha, T.A. Kurniawan, M.E.T. Sillanpää, Removal of silicon from pulping whitewater using integrated treatment of chemical precipitation and evaporation, Chem. Eng. J. 158 (2010) 369646.

[35] D. Hermosilla, R. Ordóñez, L. Blanco, E. de la Fuente, A. Blanco, pH and particle structure effects on silica removal by coagulation. Chem. Eng. Technol. 35 (2012) 1632-1640.

[36] I. Latour, R. Miranda, A. Blanco, Silica removal from newsprint mill effluents with aluminum salts. Chemical Engineering Journal (2013), doi: http://dx.doi.org/10.1016/j.cej.2013.06.039. 
Table 1.- Characteristics of papermaking process water.

\begin{tabular}{|l|c|}
\hline $\mathrm{pH}$ & 7.7 \\
\hline Conductivity, $25^{\circ} \mathrm{C}(\mathrm{mS} / \mathrm{cm})$ & 2.13 \\
\hline Total solids $(\mathrm{g} / \mathrm{L})$ & 6.59 \\
\hline Total suspended solids $(\mathrm{g} / \mathrm{L})$ & 3.35 \\
\hline Turbidity $(\mathrm{NTU})$ & 2400 \\
\hline Cationic demand $(\mathrm{meq} / \mathrm{L})$ & 1.28 \\
\hline $\mathrm{COD}(\mathrm{mg} / \mathrm{L})$ & 2280 \\
\hline $\mathrm{SiO}_{2}(\mathrm{mg} / \mathrm{L})$ & 240 \\
\hline $\mathrm{Total}$ dissolved solids $(\mathrm{g} / \mathrm{L})$ & 3.24 \\
\hline Dissolved turbidity $(\mathrm{NTU})$ & 89 \\
\hline Dissolved COD $(\mathrm{mg} / \mathrm{L})$ & 1890 \\
\hline Dissolved chlorides $(\mathrm{mg} / \mathrm{L})$ & 157 \\
\hline
\end{tabular}

Table 2.- Characteristics of chitosan products

\begin{tabular}{|c|c|c|c|c|c|}
\hline $\begin{array}{c}\text { Chitosan } \\
\text { product }\end{array}$ & $\begin{array}{c}\mathbf{M}_{\mathbf{w}} \cdot \mathbf{1 0}^{\mathbf{5}} \text {, } \\
\mathbf{g} / \mathbf{m o l}\end{array}$ & $\begin{array}{c}\mathbf{C C D}^{*} \text {, } \\
\mathbf{m e q} / \mathbf{g}\end{array}$ & $\begin{array}{c}\text { Deacetylation } \\
\text { degree, \% }\end{array}$ & $\begin{array}{c}\text { Quaternization } \\
\text { degree, \% }\end{array}$ & $\begin{array}{c}\text { pH stock } \\
\text { solution } \\
(1 \mathrm{~g} / \mathrm{L})\end{array}$ \\
\hline Ch.MMW & 2.375 & 5.75 & 86.5 & - & 4.05 \\
Ch.LMW & 0.768 & 5.44 & 85.7 & - & 4.00 \\
\hline Quat.5 & - & 2.27 & - & 72 & 6.95 \\
Quat.10 & - & 2.11 & - & 86 & 6.95 \\
\hline
\end{tabular}

Cationic charge density at the $\mathrm{pH}$ of the stock solutions determined by colloidal titration. 


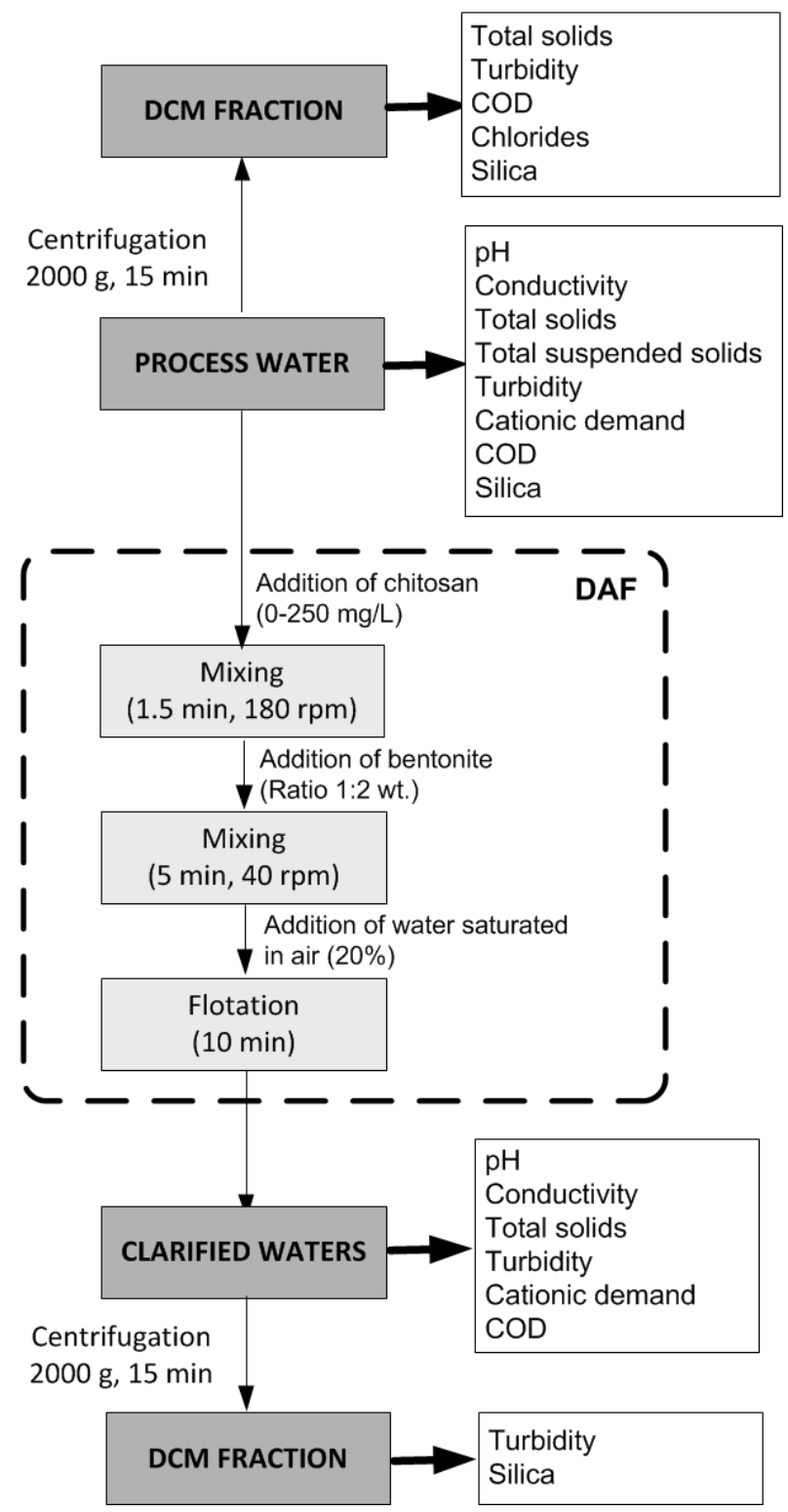

Figure 1.- Experimental protocol to evaluate the efficiency of different chemicals to remove DCM by dissolved air flotation. 


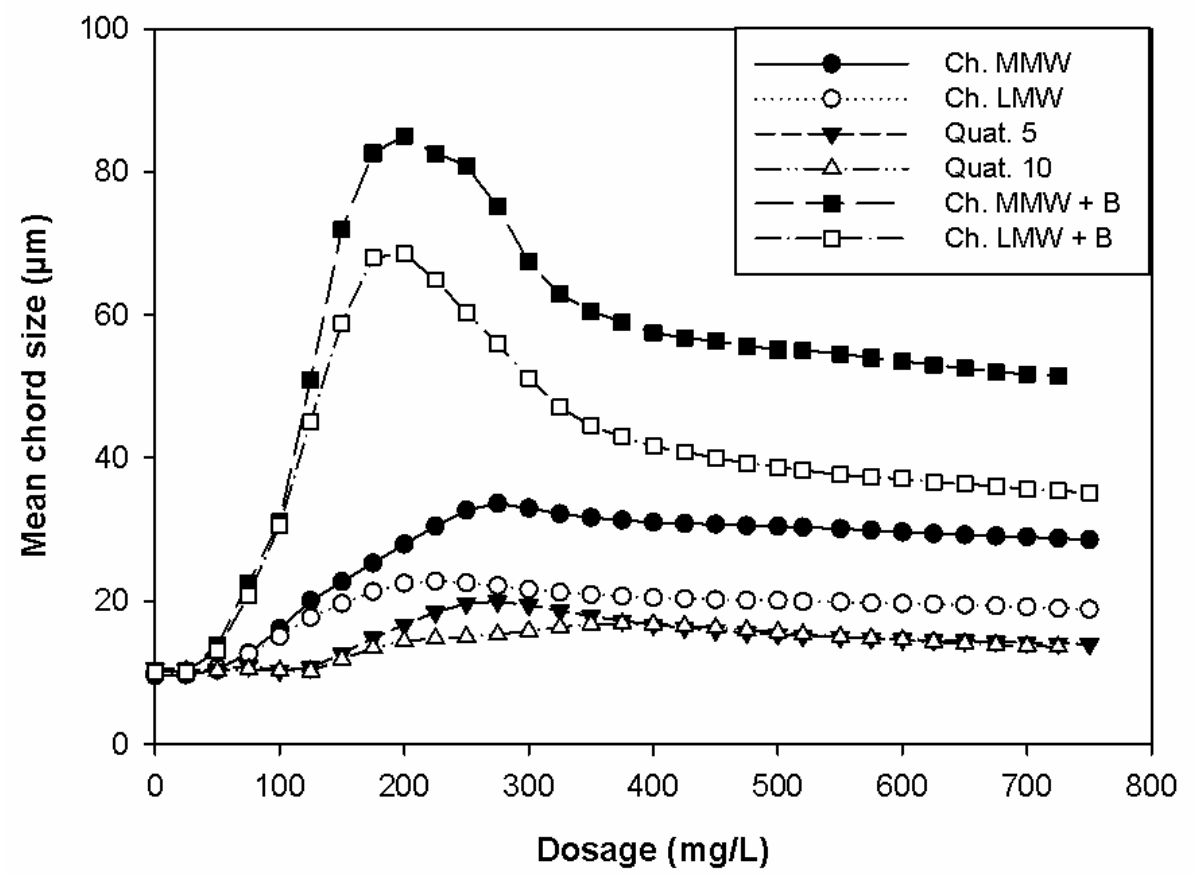

Figure 2.- Evolution of the mean chord size vs. chemicals dosage.

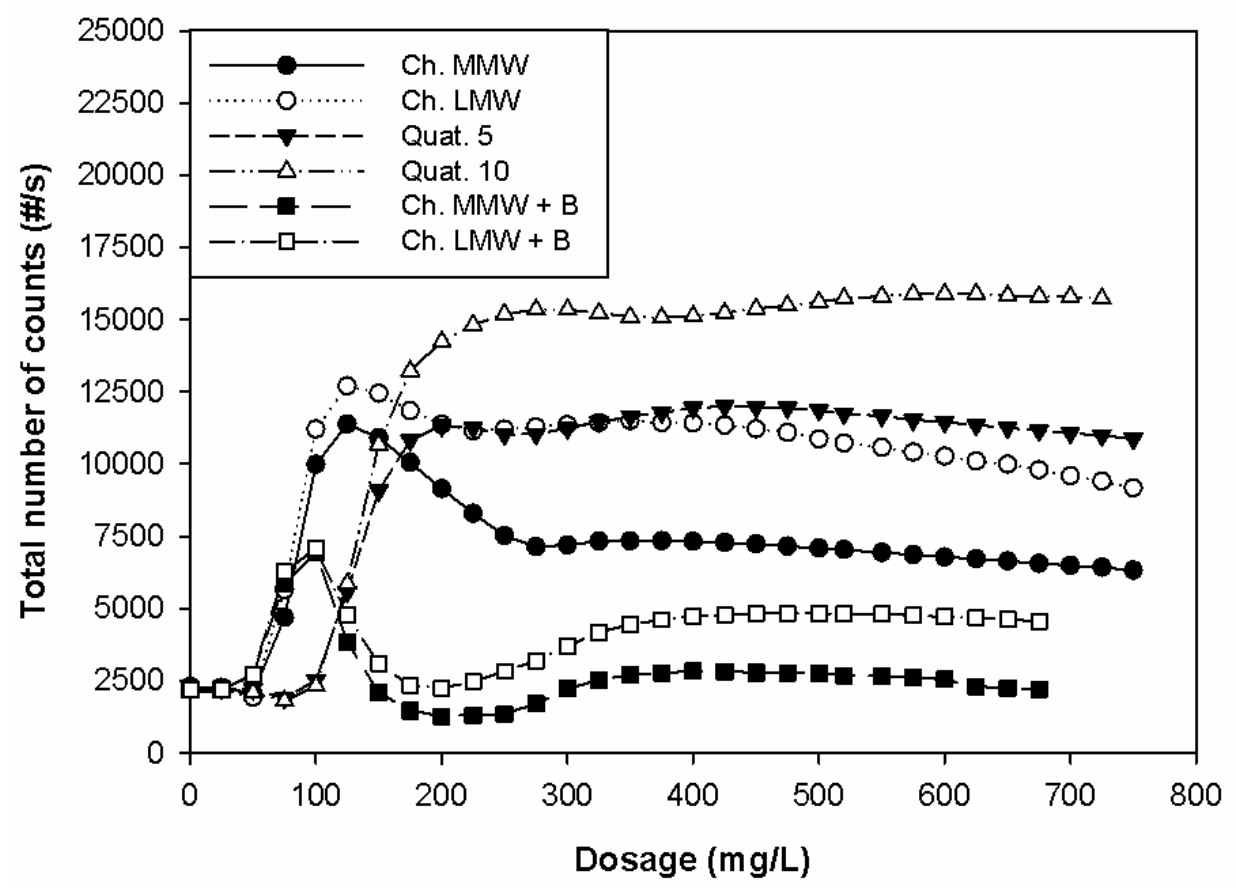

Figure 3.- Evolution of total number of counts vs. chemicals dosage. 


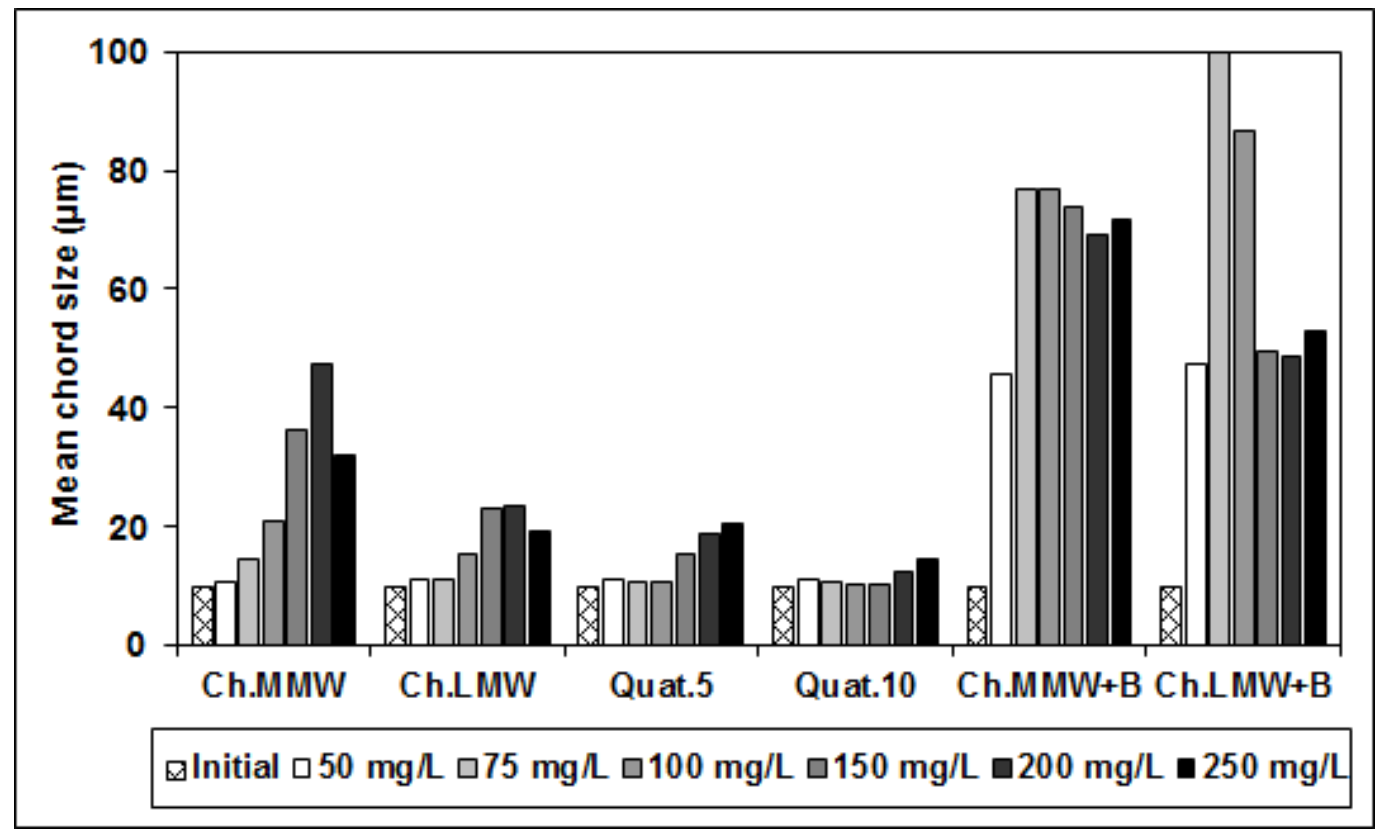

Figure 4.- Mean chord size for studied chemical systems, at different dosage levels.

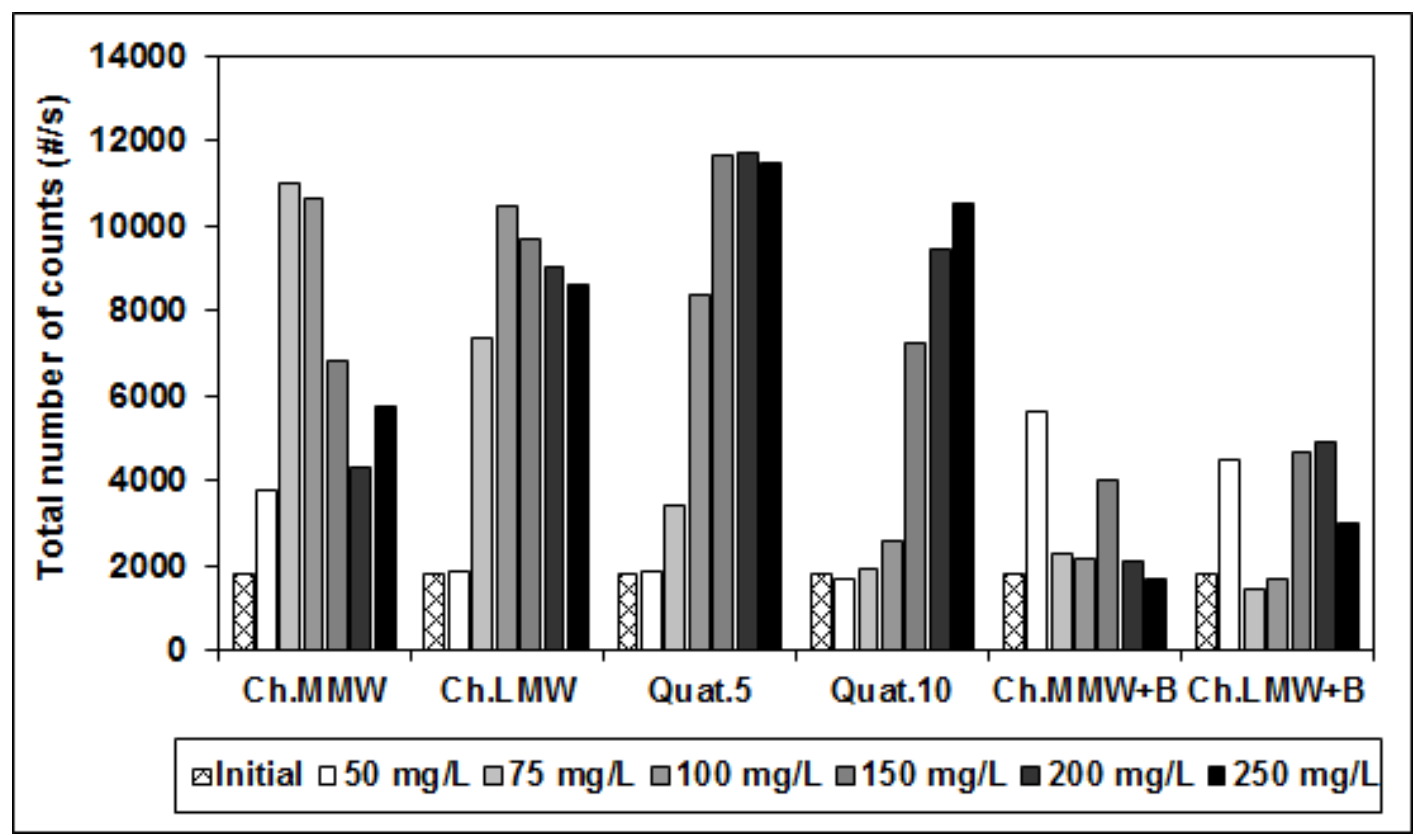

Figure 5.- Total number of counts for studied chemical systems, at different dosage levels. 
(a)

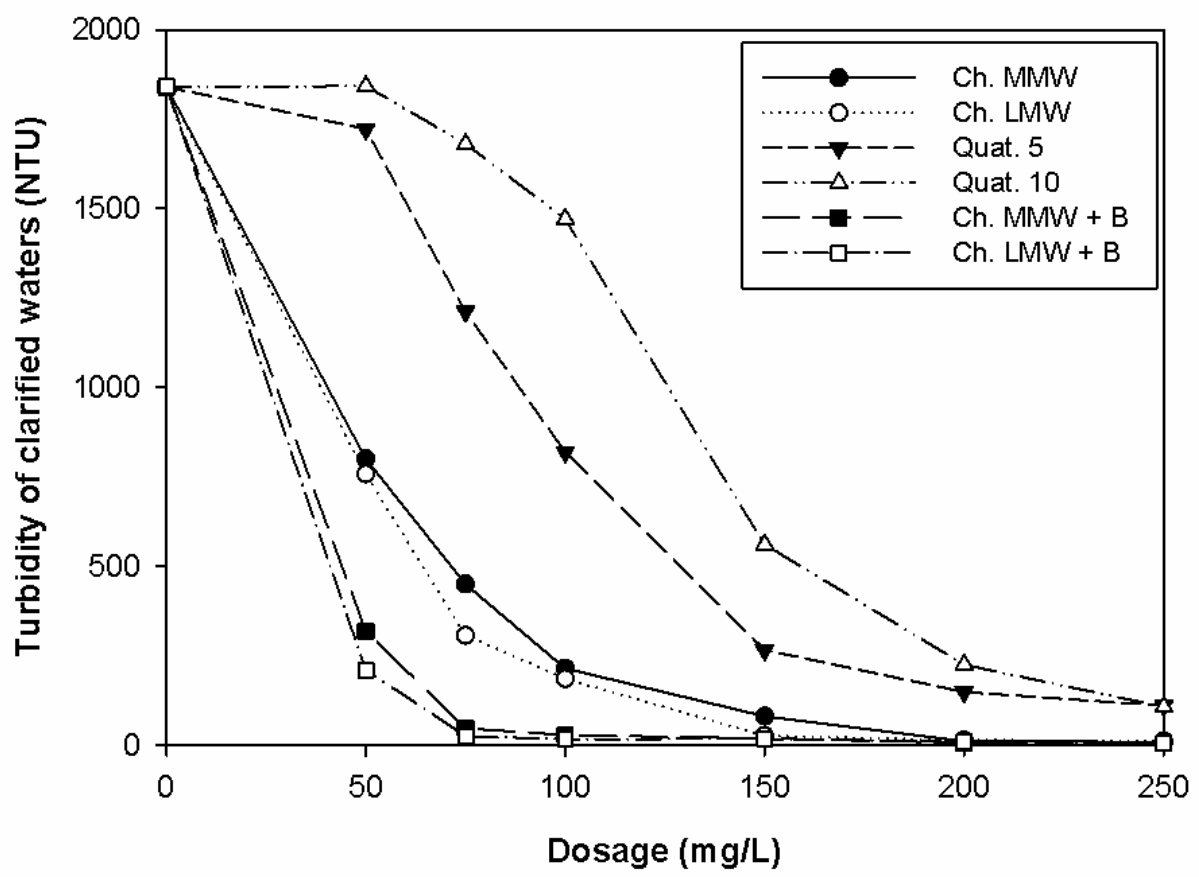

(b)

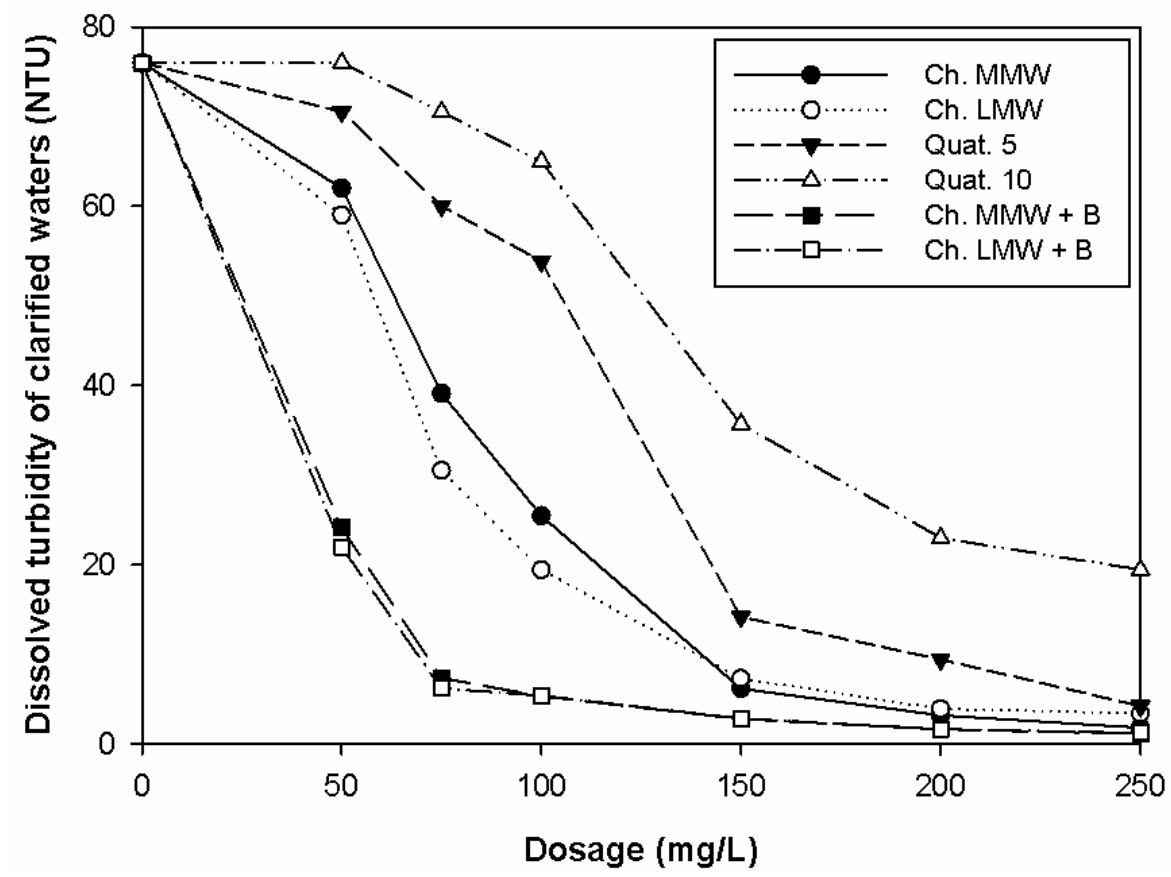

Figure 6.- Turbidity of clarified waters (a) and its dissolved fraction (b) vs. chemicals dosage. 


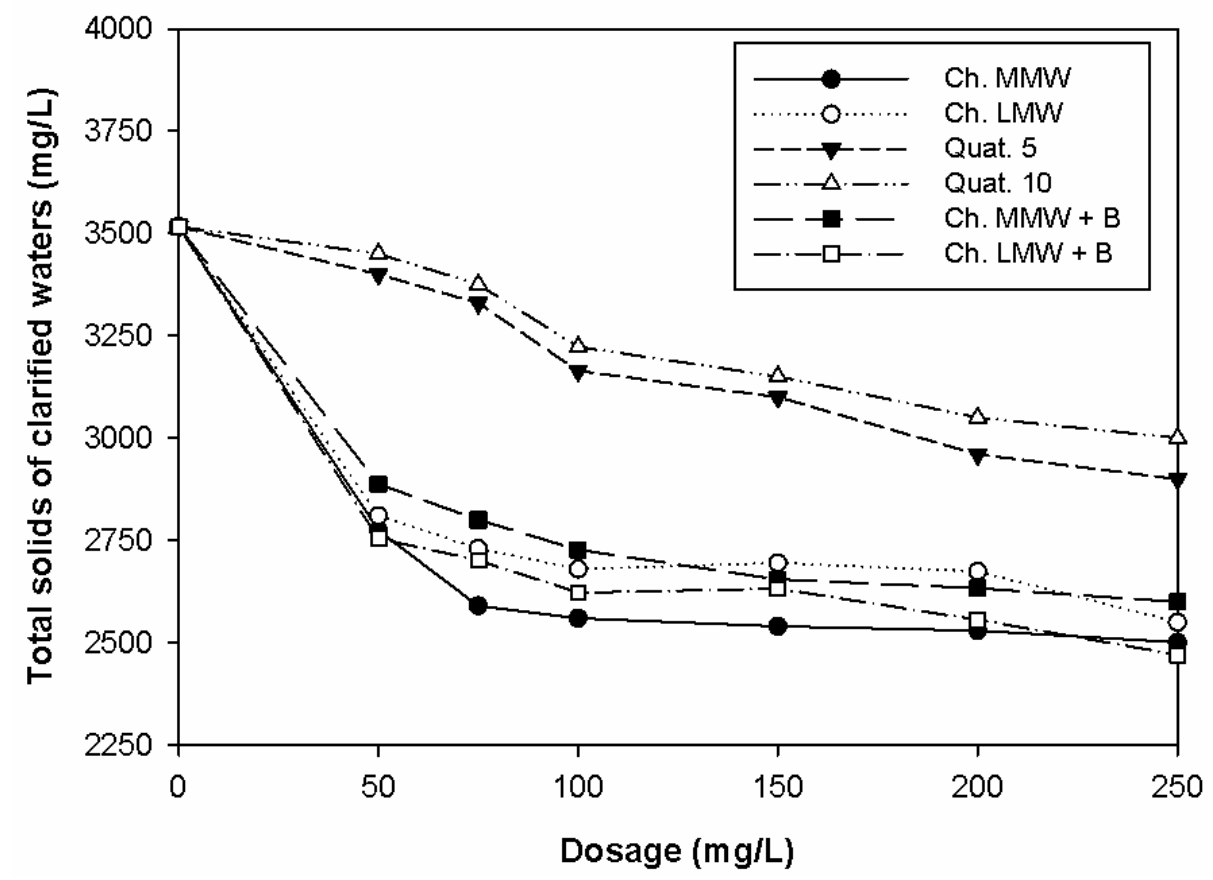

Figure 7.- Total solids of clarified waters vs. chemicals dosage.

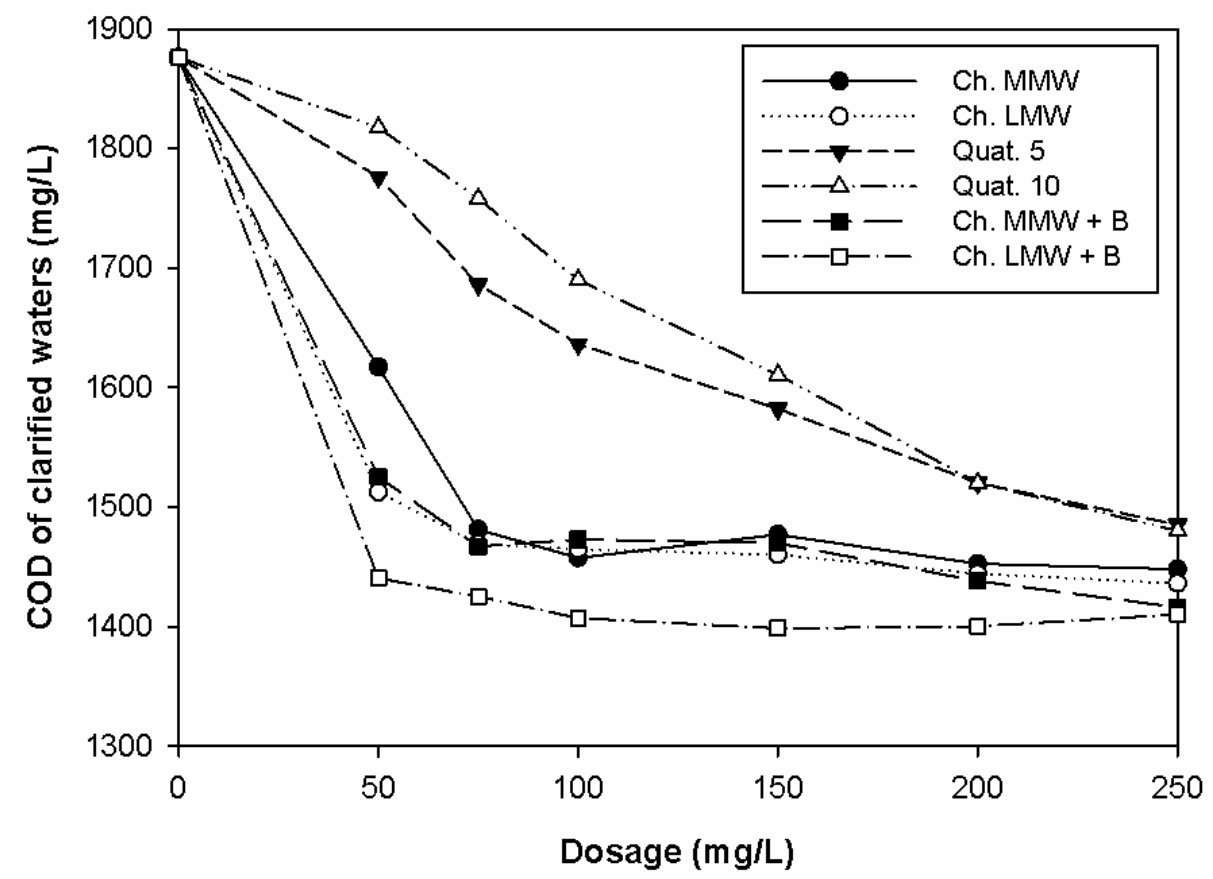

Figure 8.- COD of clarified waters vs. chemicals dosage. 


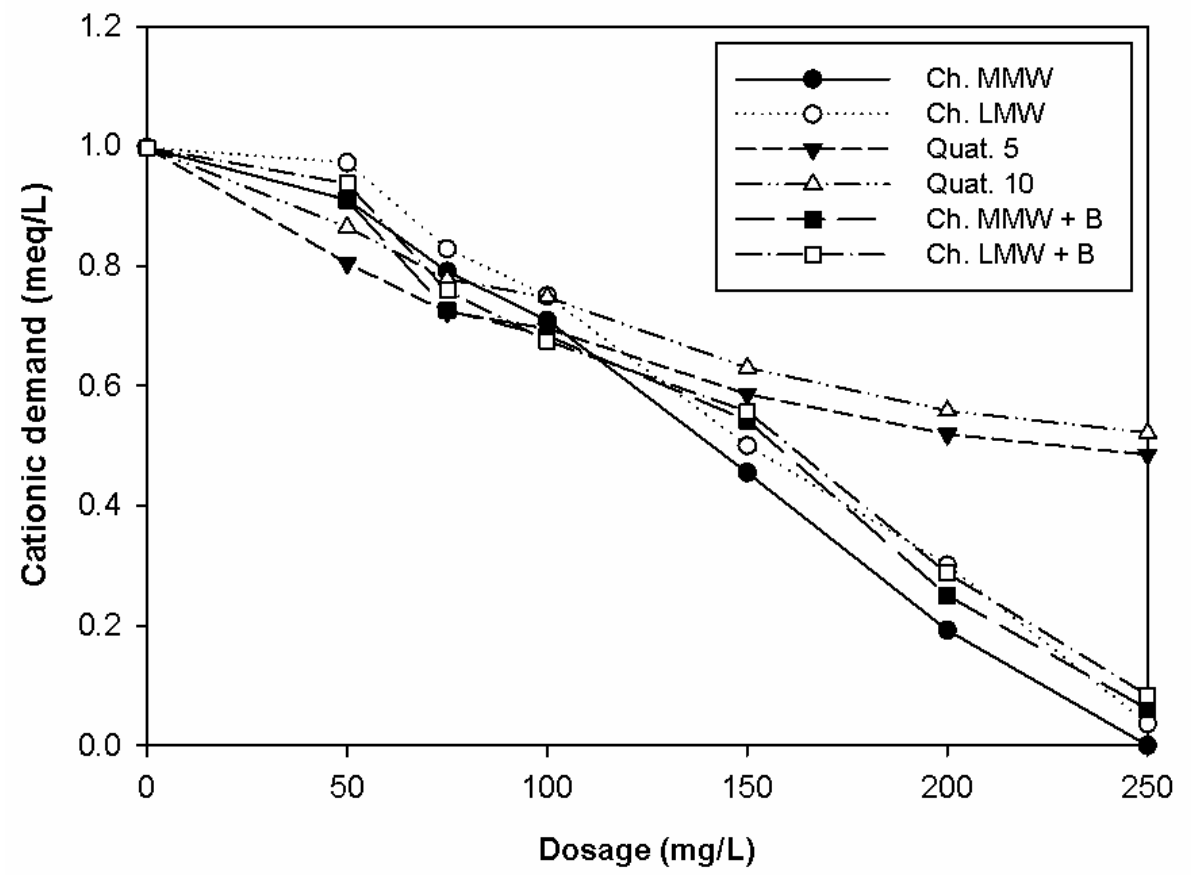

Figure 9.- Cationic demand of clarified waters vs. chemicals dosage.

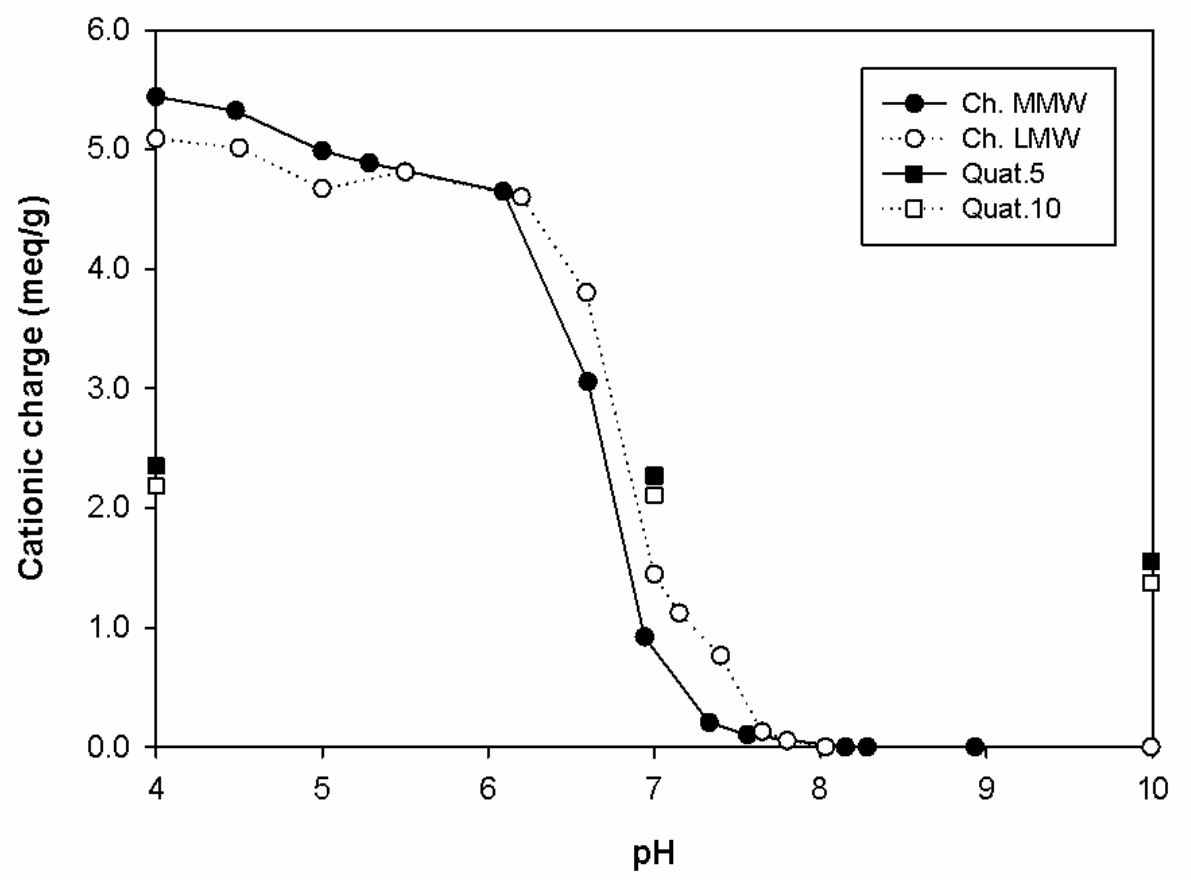

Figure 10.- Cationic charge of chitosans vs. pH. 